\title{
The root cause of periorbital lid oedema
}

\section{Ali S Haider, Matthew Gilmore, Brett Drury, Sharon Morris}

CASE

A man aged 42 years presented with a three-day history of left periorbital swelling (Figure 1). He reported intermittent pain from a left upper tooth in the preceding 18 months. He had not experienced any changes in vision, diplopia, ocular pain, headache, nasal discharge, fever, loss of appetite or fatigue.

The patient's medical history was unremarkable, and his vital signs were within normal limits. Moderate non-tender left periorbital oedema with mild lid erythema was present. He had good Snellen visual acuity of 6/6 in each eye. Both pupils were equal and reactive to light. Intraocular pressures were normal. The eyes were white with normal anterior and posterior segments.

\section{QUESTION 1}

What common conditions, with or without a red eye, can present with unilateral periorbital lid swelling, and which serious conditions need to be excluded?

\section{QUESTION 2}

What additional examination findings and investigations can be helpful at initial consultation?

\section{ANSWER 1}

Common conditions that can present with unilateral periorbital lid swelling include:
- the following presentations with a red eye

- conjunctivitis - viral (most common), bacterial or allergic

- corneal abrasions

- the following presentations without a red eye

- chalazion

- blepharitis

- skin pathology

- contact dermatitis

- herpes simplex or zoster dermatitis

- trauma

- preseptal cellulitis

- orbital fat prolapse.

Serious conditions that need to be excluded are:

- the following presentations with a red eye

- orbital cellulitis

- orbital inflammatory conditions (eg thyroid orbitopathy - usually bilateral; orbital inflammatory syndrome, dacryoadenitis)

- serious inflammatory causes of a red eye (eg keratitis, scleritis, endophthalmitis)

- the following presentations without a red eye

- early orbital cellulitis

- orbital mass (eg lymphoma, mucocoele, sarcoidosis)

- eyelid malignancy.

The differential diagnosis of periorbital oedema is broad, with a high index of suspicion for infection in unilateral cases.

\section{ANSWER 2}

It is important to test extraocular movements for signs of discomfort, restriction or diplopia. An assessment for proptosis should be made.

Ancillary testing would include:

- orthopantomogram - a quick means to assess dentition and cause for dental pain

- computed tomography (CT) scan of the orbits and facial sinuses with contrast.

\section{CASE CONTINUED}

Extraocular rotations on the right were full, but the left eye showed restriction in upgaze and superotemporal gaze, causing discomfort and diplopia. Despite appearing well, the patient's C-reactive protein was $283 \mathrm{mg} / \mathrm{L}$ (reference range $<5 \mathrm{mg} / \mathrm{L}$ ).

The CT scan showed a diffusely thickened left inferior rectus muscle with adjacent fat stranding in the postseptal region and proptosis of $2 \mathrm{~mm}$ (Figures 2A and $2 \mathrm{~B})$. Left maxillary and ethmoidal sinusitis was present. The root of the left maxillary first molar (tooth 26) lay within the maxillary sinus, and there was associated periapical radiopacity, as well

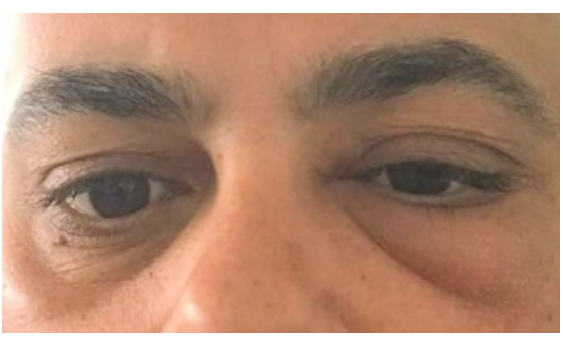

Figure 1. Left periorbital oedema causing mild ptosis and fullness over the left nasolabial fold 
as dental caries noted within tooth 26

(Figures 2C and 2D).

The patient was diagnosed with orbital cellulitis.

\section{QUESTION 3}

What are the features of orbital cellulitis, and how would you exclude an orbital compartment syndrome (OCS)?

\section{QUESTION 4}

Is it common for teeth to cause maxillary sinusitis? What is the treatment of odontogenic maxillary sinusitis?

\section{ANSWER 3}

Orbital cellulitis is a sight-threatening and potentially fatal medical emergency referring to intraorbital spread of infection beyond the orbital septum, a thin connective tissue membrane partitioning the superficial eyelid from deeper orbital structures. ${ }^{1}$ Orbital cellulitis may present with varying degrees of lid oedema. It has classically been described as a painful red eye with tense periorbital swelling, restriction or pain with eye movements, proptosis and signs of optic nerve dysfunction in severe cases (reduced visual acuity, colour vision, with or without a relative afferent pupillary defect [RAPD]). Patients are often systemically unwell.

OCS refers to a dangerous rise in intraorbital pressure exceeding perfusion pressure of the ophthalmic artery that can lead to irreversible vision loss if not treated by emergent canthotomy and
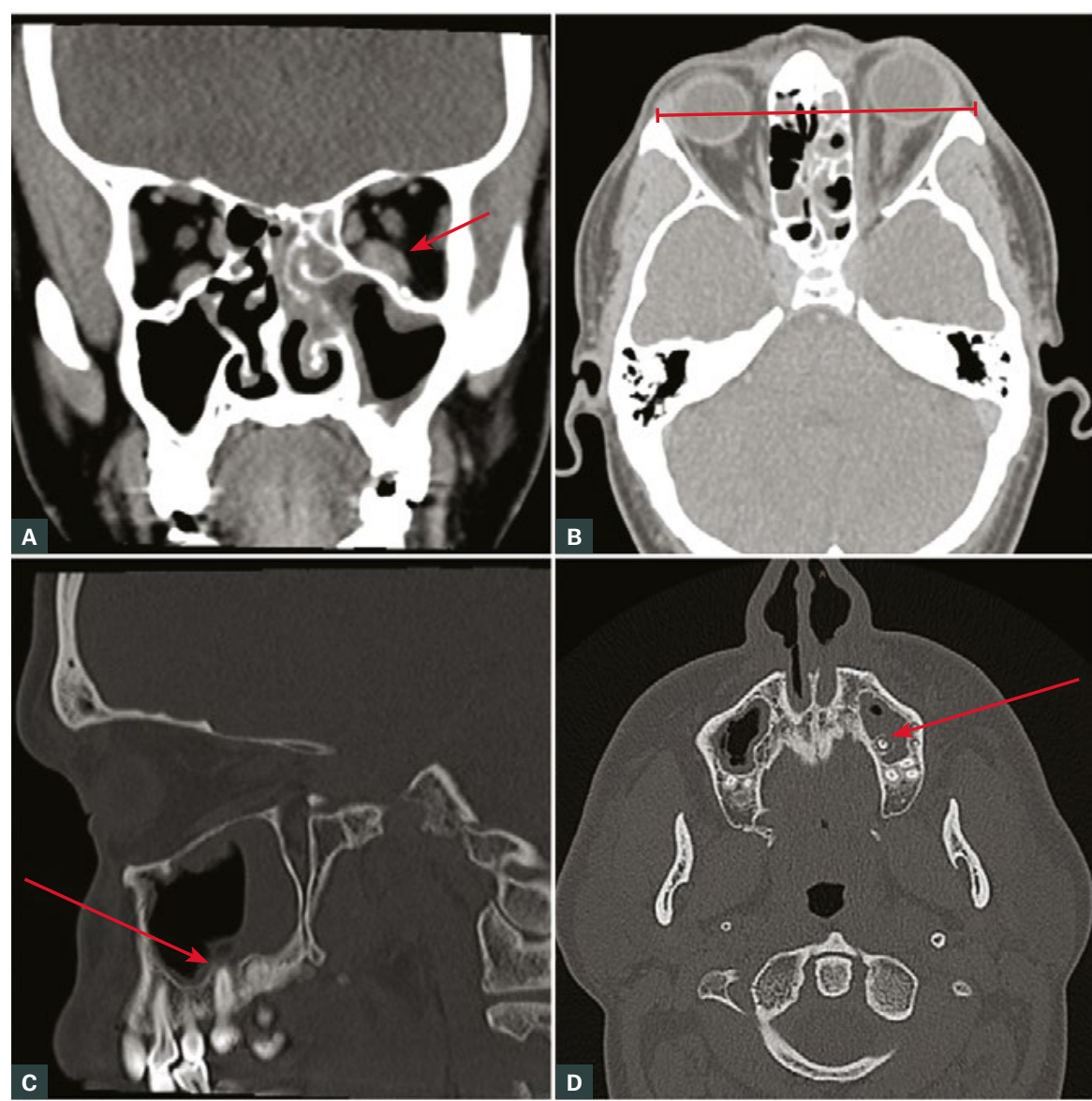

Figure 2. Computed tomography images with arrows highlighting the following features

A. Enlarged left inferior rectus muscle (coronal view); B. Left proptosis (axial view); C. \& D. Tooth within left maxillary sinus with consequent sinusitis (sagittal and axial views)

cantholysis. ${ }^{2}$ It is most commonly seen following trauma or orbital surgery but can occur less commonly in a 'hot orbit' from orbital cellulitis. Important clinical findings include markedly elevated intraocular pressure ( $>40 \mathrm{mmHg}$ ) with or without decrease in visual acuity, proptosis and reduced extraocular movements. Increased resistance of the affected globe to digital retropulsion can be used to assess the tenseness of the orbit, with a firm globe suggestive of raised intraocular pressure..$^{2,3}$

\section{ANSWER 4}

There is a close anatomical relationship between the roots of posterior maxillary teeth, commonly the maxillary first molar, and the maxillary sinus. Pulpal infection may result from dental caries, trauma or periodontal disease. This may be the source of ongoing infection, most commonly a periapical abscess. If the apices of the molar teeth lie in proximity to the maxillary sinus, sinusitis can result.

Paranasal sinus infection is the most common cause of orbital cellulitis ${ }^{4-6}$ with the maxillary sinus particularly susceptible as its drainage orifice is vulnerably positioned near the roof of the sinus. ${ }^{4}$

While orbital cellulitis is a relatively rare complication of dental infection, maxillary sinusitis is a common complication, and it is important that practitioners have a high index of suspicion in all patients presenting with tooth pain and symptoms of maxillary sinusitis. ${ }^{7}$

Definitive treatment of symptomatic irreversible pulpitis is through either root canal therapy (removing the infected pulp and replacing it with a biomaterial) or extraction. Antibiotics play a part but will not eliminate the reservoir of bacteria within the infected pulp. Consequently, all patients with lingering dental pain should have prompt dental assessment. As a result of the polymicrobial nature of dental infections, antimicrobial treatment should commence with a broad-spectrum antibiotic (eg amoxycillin with clavulanic acid) and narrow to an appropriate antibiotic after culture and sensitivity results are returned.

Early referral for interdisciplinary care between an ophthalmologist; oral and maxillofacial surgeon; and an ear, nose 
and throat specialist is vital to ensure optimum patient outcomes in suspected cases of odontogenic orbital cellulitis.

\section{CASE CONCLUDED}

The patient was admitted to hospital for intravenous antibiotics, dexamethasone and intranasal sinus cares. Surgical extraction of tooth 26 was performed by the maxillofacial team, with rapid improvement in orbital symptoms.

\section{Key points}

- Orbital cellulitis is a sight-threatening and potentially fatal medical emergency.

- Imaging is essential as the distinction between preseptal and postseptal cellulitis can be difficult, and sinus disease may have a silent presentation.

- This case highlights the importance of assessing for painful eye movements, gaze restriction and/or proptosis - more specific signs of this condition.

- It is important that practitioners have a high index of suspicion in all patients presenting with tooth pain and symptoms of maxillary sinusitis.

- Early referral is vital to ensure optimum patient outcomes in suspected cases of odontogenic orbital cellulitis.

\section{Authors}

Ali S Haider BMedSc, MBBS, MMed (OphthSc), Ophthalmology Principal House Officer, Department of Ophthalmology, Gold Coast University Hospital, Southport, Qld

Matthew Gilmore BBiomedSc, MBBS, BOH (DentSci), GradDipDent, MSurg, Oral and

Maxillofacial Surgery Principal House Officer,

Department of Oral and Maxillofacial Surgery, Gold

Coast University Hospital, Southport, Qld

Brett Drury BAppSci (Optom), MBBS, FRANZCO,

Ophthalmologist, Department of Ophthalmology,

Gold Coast University Hospital, Southport, Qld

Sharon Morris BM, MRCSEd, FRCOphth, FRANZCO, Ophthalmologist, Department of Ophthalmology,

Gold Coast University Hospital, Southport, Qld

Competing interests: None.

Funding: None.

Provenance and peer review: Not commissioned, externally peer reviewed.

Correspondence to:

alihaider@live.com.au

\section{References}

1. Gordon AA, Phelps PO. Management of preseptal and orbital cellulitis for the primary care physician.
Dis Mon 2020;66(10):101044. doi: 10.1016/j. disamonth.2020.101044.

2. McCallum E, Keren S, Lapira M, Norris JH. Orbital compartment syndrome: An update with review of the literature. Clin Ophthalmol 2019;13:2189-94. doi: 10.2147/OPTH.S180058.

3. Nassr MA, Morris CL, Netland PA, Karcioglu ZA. Intraocular pressure change in orbital disease. Surv Ophthalmol 2009;54(5):519-44. doi: 10.1016/j.survophthal.2009.02.023.

4. Sharma V, Chhangte L, Joshi V, Gupta S, Kalpana. A case of odontogenic orbital cellulitis causing blindness: A case report. Delhi J Opthalmol 2013;24:102-05. doi: 10.7869/djo.2013.22.

5. Snell RS, Lemp MA. Clinical anatomy of the eye. 2nd edn. Malden, MA: Blackwell Science, 1998.

6. Youssef $\mathrm{OH}$, Stefanyszyn MA, Bilyk JR. Odontogenic orbital cellulitis. Ophthalmic Plast Reconstr Surg 2008;24(1):29-35. doi: 10.1097/ IOP.0b013e318160c950.

7. Beech N, Goh R, Lynham A. Management of dental infections by medical practitioners. Aust Fam Physician 2014;43(5):289-91. 